Article

\title{
Overview of Thermal Hydraulic Optimization and Verification for the EU-DEMO HCPB BOP ICD Variant
}

\author{
Wolfgang Hering *(D), Evaldas Bubelis, Sara Perez-Martin (D) and Maria-Victoria Bologa
}

Citation: Hering, W.; Bubelis, E.;

Perez-Martin, S.; Bologa, M.-V.

Overview of Thermal Hydraulic

Optimization and Verification for the EU-DEMO HCPB BOP ICD Variant.

Energies 2021, 14, 7894. https://

doi.org/10.3390/en14237894

Academic Editors: Alessandro Del

Nevo and Marica Eboli

Received: 29 October 2021

Accepted: 19 November 2021

Published: 25 November 2021

Publisher's Note: MDPI stays neutral with regard to jurisdictional claims in published maps and institutional affiliations.

Copyright: (c) 2021 by the authors. Licensee MDPI, Basel, Switzerland. This article is an open access article distributed under the terms and conditions of the Creative Commons Attribution (CC BY) license (https:// creativecommons.org/licenses/by/ $4.0 /)$.
Karlsruhe Institute of Technology (KIT), Institute for Neutron Physics and Reactor Technology (INR), Hermann-von-Helmholtz-Platz 1, 76344 Eggenstein-Leopoldshafen, Germany; evaldas.bubelis@kit.edu (E.B.); sara.martin@kit.edu (S.P.-M.); maria-victoria.bologa@kit.edu (M.-V.B.)

* Correspondence: wolfgang.hering@kit.edu; Tel.: +49-721-608-22556

\begin{abstract}
When progressing from the International Thermonuclear Experimental Reactor (ITER) to the Demonstration Fusion Reactor (DEMO), a system for transferring plasma heat exhaust to a power conversion system is necessary for the so-called Balance of Plant (BOP). During the preconceptual phase of the EU-DEMO project, different BOP concepts were investigated in order to identify the main requirements and feasible architectures to achieve that goal in the most efficient way. This paper comprises the investigations performed during the DEMO preconceptual design phase (p-CDP) and compares the different variants. The main aspect was focused on the helium-cooled pebble bed (HCPB) breeding blanket (BB) concept. After all assessments were performed, the indirect coupled design (ICD) was chosen as the reference configuration for the DEMO HCPB BOP for further development and optimization. The ICD provides decoupling using a molten salt storage loop, which accumulates thermal power during plasma pulses that are released during dwell periods. The work is supported by simulations using design codes EBSILON and MATLAB/SIMULINK, providing the basis for the next design phase.
\end{abstract}

Keywords: EU-DEMO; helium-cooled pebble bed; balance of plant; thermal storage; indirect coupled design; energy balance; power conversion system; simulation

\section{Introduction}

Following the Karlsruhe Institute of Technology (KIT) activities with respect to the helium-cooled pebble bed ( $\mathrm{HCPB})$ breeding blanket $(\mathrm{BB})$ design, the contribution to the EUROfusion balance of plant (BOP) work package was initiated in 2012. The focus was on the development of the future DEMO plant to address the needs of the future. The BOP of DEMO was one of the new main topics to be investigated, since ITER is not designed to generate any electrical power. The DEMO power plant has to demonstrate electricity production for future electrical grids in a stable, predictable, and reliable manner [1]. Since EUROfusion uses many abbreviations, an explanative acronym list is added at the end of the paper.

DEMO as a TOKAMAK fusion reactor operates in pulsed mode with expected cycles of $2 \mathrm{~h}$ long plasma operation (pulse) followed by 10 min dwell time, necessary to clean, refuel, and reload the central solenoid. Although the dwell time between pulses has been significantly reduced thanks to cutting-edge technologies for solenoid loading and vacuum pump capacity, the intermittent thermal power implies an intermittent electrical power output. Various options were explored along the years to handle the requirements and demands of the future DEMO powerplant, leading to direct coupled designs (DCDs) and indirect coupled designs (ICDs) [2]. Among the proposed solutions, that including an energy storage system (ESS) based on commercial systems already operating in concentrating solar power (CSP) plants was the most robust. However, other options were proposed, assuming smaller or even no energy storage in order to evaluate robustness, feasibility, reliability, and technological readiness. 
The preconceptual design phase ( $\mathrm{p}-\mathrm{CDP}$ ) considers not only the required characteristics of the BOP system, but also the framework in which the DEMO plant will be constructed and operated by the middle of the century. Taking into account the EU projection for the greenhouse gas emission reduction by 2050 [3], the renewable energy share will provide most of the electric energy. Bringing fusion powerplants (FPP) to the market will imply added value to power production, especially by balancing the enormous share of variable renewable energy sources (VRES) by load following operation and sector coupling. This means that FPPs will be welcomed if they support grid stability. Today, this concept is considered in advanced nuclear powerplants, where innovative reactor designs feature energy storage systems to handle the dynamics of the electrical grid [4].

The balance of plant work package in the EU-DEMO Project [1] investigates the transfer of plasma power from the breeding blanket to electricity to be delivered to plant systems, as well as to the grid via the plant electrical system (PES) [2]. This involves adequate cooling systems of different fluids and an efficient heat transfer across heat exchangers. Additionally, secondary heat sources from divertor (DIV) and vacuum vessel $(\mathrm{VV})$ are used as additional feedwater heating to enhance the efficiency of the power conversion system (PCS) and avoiding investment toward additional cooling capacity of the component cooling water system. The system was designed on the basis of existing industrial technology.

In the selected design variant, an intermediate heat transfer and storage (IHTS) system including a thermal energy storage system decouples the helium-based primary heat transfer system (PHTS) from a highly efficient PCS designed by industry.

In this paper, the design solutions and the challenges are discussed for the heliumcooled pebble bed concept described in Section 2. In Section 3, the reference version is described. In Section 4, the focus is on the experimental facility, necessary to select BOP components and to test the interplay of the different thermal hydraulic cooling systems (i.e., PHTS, IHTS and PCS). In Section 5, a summary and conclusions complete the paper.

\section{DEMO НСРB BOP Architecture}

In the preconceptual design phase, several variants were investigated focusing on an efficient operation and easy integration into future energy systems in Europe and worldwide. This implies some requirements since the climate crisis stimulates steadily increasing shares of variable renewable energy sources and the replacement of fossil fuels in the heat market by electricity or solar heat, if available. This requires active control and an energy storage system. To select the best DEMO HCPB BOP option for the given boundary conditions, a total of four variants were investigated to different extents.

BOP interacts with most of the other DEMO systems as indicated in Figure 1. This indicates some constraints with respect to plant power demand during different operating phases, especially during the dwell time when only $1 \%$ of the full power is released to the PHTS.

The most critical interface is between the breeding blanket (inside vacuum vessel) and BOP, which is located geometrically at the water-cooled VV wall. From the BOP control point of view, the BB is a passive system, transferring plasma power to the heat transfer fluid (HTF). BB designers specify the tolerable temperature range and the power to be exhausted to the BB-PHTS. BOP, via the BB-PHTS, delivers a mass flow rate of helium to keep the temperature within the tolerable range. Another important requirement is the system pressure, which has to be controlled by BOP.

BOP design should provide operability of the powerplant during all possible DEMO plant states, i.e., plasma operation (pulse: $2 \mathrm{~h}$ ) and dwell time (10 min). Maintenance (shortand long-term) was not considered in the $\mathrm{p}$-CDP. In addition, safety functions were defined to manage failures and to reduce risks. The transitions between plasma operation states (pulse-to-dwell: P2D and dwell-to-pulse: D2P) are the most challenging issues for DEMO design. Thus, the BOP investigation was focused on (i) identifying the critical items of the whole $\mathrm{BOP}$ concept, (ii) proposing and assessing solutions to minimize the effects of the 
P2D and D2P transitions, and (iii) concluding and recommending the best solution on the basis of validated system code results and industrial experience. The other main interface is the DEMO plant electrical system. It was defined to be located at the shaft between the turbine and electric generator, providing power to the plant internal demand and the grid.

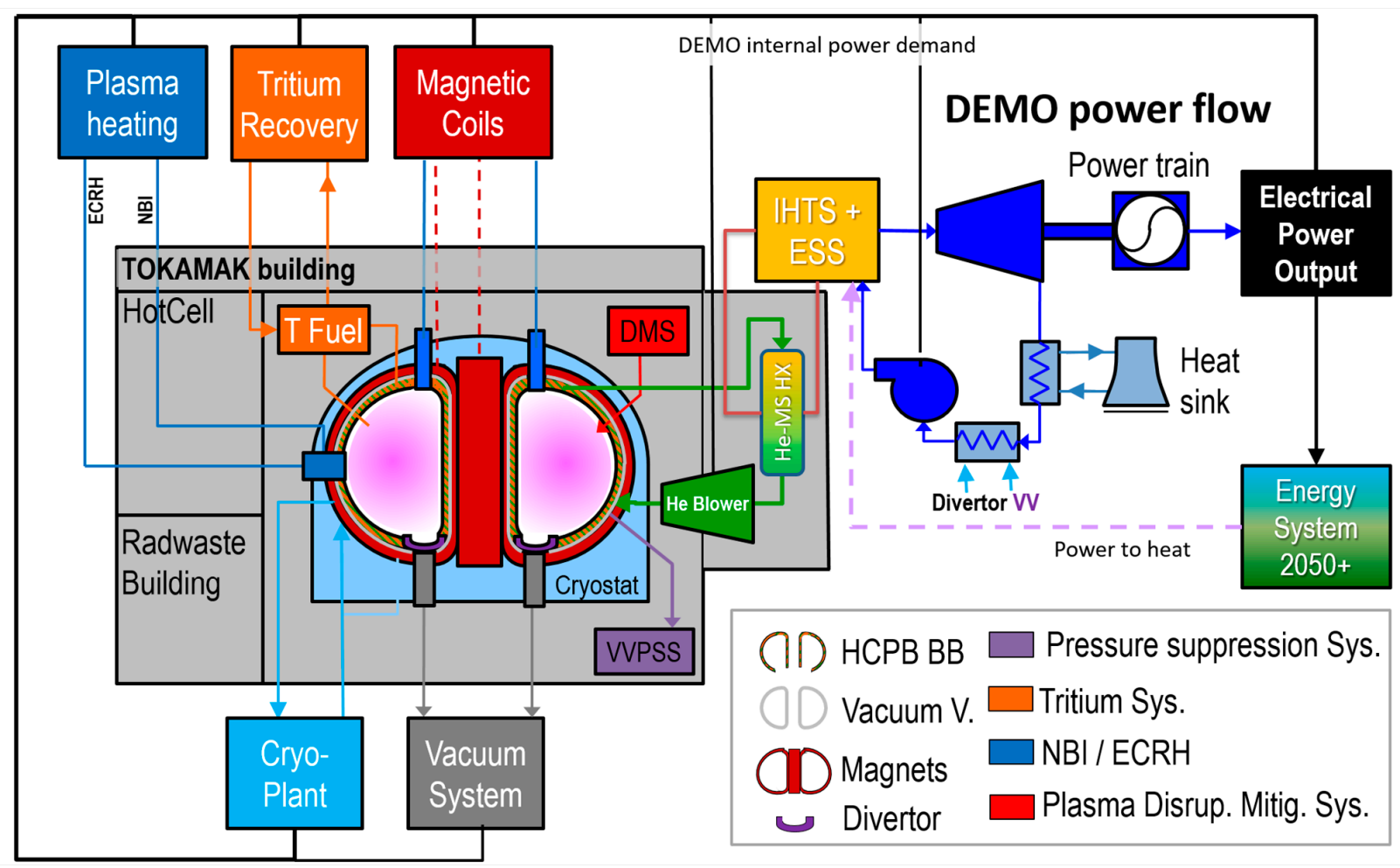

Figure 1. Overview and interfaces of DEMO systems (selected variant HCPB BOP ICD).

Variants Investigated: The two main requirements considered in the variant assessment (see Table 1) were (i) to avoid disconnection from the grid for each pulse/dwell transition, and (ii) to reduce the impact of frequent temperature transients to structures. Moreover, integration, performance, safety, and cost aspects were taken into account in the integral analysis performed for each variant.

Table 1. DEMO HCPB BOP variants investigated during pre-conceptual design phase [5].

\begin{tabular}{cc}
\hline Name & Explanation \\
\hline DIRECT-AUXB (DCD-1) & Direct PHTS-PCS coupling but including a gas fired \\
auxiliary boiler
\end{tabular}

Generally, all possible solutions were investigated focusing on feasibility, applicability, and safety consequences. The three direct coupled variants: Direct-AUXB (DCD-1), DirectSmall ESS (DCD-s1), and Direct-Small ESS (DCD-s2), had several drawbacks with respect to the requirements mentioned above.

The first DCD case investigated was Direct-AUXB (DCD-1), where the avoidance of loss of synchronization during dwell was accomplished using a gas-fired boiler that pro- 
vides steam flow to the turbine and maintains the power train in operation. The boiler size is directly proportional to the minimum steam flow rate needed by the turbine. Depending on the turbine concept considered, different lowest operation power levels can be achieved keeping the frequency constant. The key challenge in this DCD-1 case is, however, to manage the fast P2D and D2P transients, while operating the turbine in a safe way. On the other hand, the auxiliary boiler power has to reach the level of several hundred MW during dwell time, which implies an additional infrastructure (included in the auxiliary heater section (AHS)), similar to a small gas-fired power station requiring rather large gas pipelines. Another drawback of this case is the temperature and pressure transients achieved in the boiler during pulsed operation, which add additional difficulties to the boiler operation. All these facts together with the needs to assess the costs, dimensioning, and thermal power limitations were the reasons to keep this option as a secondary solution.

The second DCD case investigated was Direct-Small ESS (DCD-s1). This variant collects part of the BB thermal energy during the pulse and stores it in a solid-state ESS for use during the dwell time. This option reduces the boiler size and DEMO power output such that this case is more realistic. A main challenge is, however, that the hightemperature-concrete ESS has difficulties in providing the thermal energy stored in a relatively short time as required for the dwell time. Additionally, the control system and pipelines increase the complexity of the system. Another aspect considered applies to the safety function. The solid ESS working as an HX stores heat from PHTS helium on one side and provides heat to the PCS water/steam during dwell time. Thus, the PHTS safety function could not be assured due to the spatial needs of the ESS. Therefore, further investigations will be needed, and this case was classified as a possible back-up solution, as with the previous DCD-1 case.

The third DCD case investigated was Direct-Small ESS (DCD-s2). This variant developed by industry uses HITEC ${ }^{\text {TM }}$ molten salt (approximately $400 \mathrm{~m}^{3}$ ) and an electrical heater ( $41 \mathrm{MWe}$ ) ahead of the hot ESS tank. This allows maximizing the electrical power production during pulse while maintaining the electrical generator synchronized to the grid during dwell phases, whereby a future steam turbine is being designed to operate at a minimum load of $10 \%$. All auxiliary components belonging to PCS are concentrated in the AHS section.

The HCPB BOP reference design variant was the indirect coupled design called HCBPICD, which uses an IHTS operating with HITEC ${ }^{\mathrm{TM}}$ to decouple the thermal power coming from the BB/FW from the PCS operation. The IHTS design was based on the current technology used in concentrating solar power (CSP) plants (150 MWe power and up to $1 \mathrm{GWh}_{\text {th }}$ storage energy). The overall analysis of this variant performed so far considered not only the feedback from the industry to improve the design focusing on the different primary heat transfer systems from BB, DIV, and VV, but also the PCS configuration to find reasonable answers to the challenges and requirements. Thus, this HCPB-ICD option was selected as the reference variant for the next step of DEMO development. Further details of this DEMO HCPB BOP variant are presented in Section 3.

The main characteristics and critical issues for each studied HCPB variant are compiled in Table 2, which includes the major topics of each heat transfer loop, namely, PHTS, IHTS-ESS, and PCS. The colors identify the current feasibility of the corresponding component, where a green color denotes the highest degree of present industrial readiness, as supported by industry. Considering all technological aspects, as well as the response of the various $B O P$ variants to the DEMO requirements, the highest ranked design was the ICD variant. It provides not only the most reliable and stable electricity production without any supplementary source, but also inherently provides more safety barriers against tritium and ACP release. 
Table 2. DEMO HCPB BOP variants investigated during pre-conceptual phase [5].

\begin{tabular}{|c|c|c|c|c|c|}
\hline System & Subsystem/Component & DCD-1 & DCD-s1 & DCD-s2 & ICD \\
\hline \multirow{2}{*}{ 总 } & BB PHTS-IHTS/PCS & He-water SG & He-water SG & He-water SG & He-MS HX \\
\hline & BB PHTS HX/SG pressure & High & High & High & Low $\sim 6$ bar \\
\hline \multirow{6}{*}{ 点 } & IHTS/ESS fluid & No & No & MS & MS \\
\hline & IHTS/ESS storage capacity & - & - & $2 \times 400 \mathrm{~m}^{3}$ & $2 \times 3000 \mathrm{~m}^{3}$ \\
\hline & Other thermal storage & No & SS Concrete & No & No \\
\hline & Auxiliary heating system & Gas (220 MWth) & Gas (93 MWth) & Electric (41.2 MWe) & No \\
\hline & Gas-fired boiler supply & Large & Medium & No & No \\
\hline & Space for aux. heating syst./IHTS & Large (aux.) & Large (aux. + conc.) & Medium (elec. + ESS) & $\begin{array}{c}\text { Large } \\
\text { (IHTS-ESS) }\end{array}$ \\
\hline \multirow{3}{*}{$\bigcup_{0}^{\infty}$} & Turbine loads & Frequent ramps & Frequent ramps & Steep ramps & Steady \\
\hline & System feasibility & TBI & No 1 & TBI & Yes \\
\hline & Tolerant to frequent transients & TBI & No & TBI & TBI \\
\hline \multirow{2}{*}{ 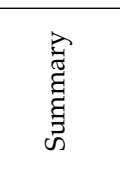 } & Critical components & $\begin{array}{c}\text { Ext. gas boiler } \\
\text { He-water HXs (FW) } \\
\text { ST }\end{array}$ & $\begin{array}{c}\text { SS concrete ESS } \\
\text { He-water HXs (FW) }\end{array}$ & \multirow[t]{2}{*}{$\begin{array}{c}\text { He SG } \\
\text { MS SG } \\
\text { He-water HXs (FW) } \\
\text { ST } \\
\text { +Ele. Power }\end{array}$} & $\begin{array}{c}\text { He-MS HX } \\
\text { MS SG } \\
\text { PCS HXs (FWH) }\end{array}$ \\
\hline & Supplementary power needed & + Gas & + Gas & & No \\
\hline Safety & Safety barriers $(\mathrm{T}, \mathrm{ACP})$ & 1 & 1 & 1 & 2 \\
\hline Red: & \multirow{3}{*}{\multicolumn{2}{|c|}{$\begin{array}{l}\text { Critical issue (size, feasibility, ... ) } \\
\text { Near or at present feasible and producible } \\
\text { be investigated further }\end{array}$}} & Blue: & \multirow{3}{*}{\multicolumn{2}{|c|}{$\begin{array}{l}\text { producible but not on shelf } \\
\text { component from shelf }\end{array}$}} \\
\hline Orange: & & & Green: & & \\
\hline & & & & & \\
\hline
\end{tabular}

\section{Reference Version: Indirect Coupled Design (HCPB-ICD)}

To prove the feasibility of the selected reference variant, industrial expertise was included to verify the most appropriate BOP variant for the DEMO fusion reactor-HCPBICD. Schematically, this variant is presented in Figure 2.



Figure 2. Overview of the DEMO HCPB ICD variant with PHTS, IHTS, and PCS indicating the different HTFs and the interfaces (dashed lines). 


\subsection{Results of Simulations}

As the first step, simulations of the HCPB-ICD variant were performed using EBSILON software in order to come up with a feasible BOP configuration. Later, the fixed HCPB-ICD configuration was tested dynamically using a MATLAB/SIMULINK model.

\subsubsection{EBSILON Simulation Results}

The HCPB-ICD conceptual design was developed assisted by the industrial tool EBSILON as shown in Figure 3 for the pulse time operation. During pulse time, $90 \%$ of the generated power by the plasma in the BB is delivered to the PCS, while $10 \%$ is stored in the ESS. During dwell time, the ESS releases energy to the PCS, thus suppling $104 \%$ ( $\sim 890 \mathrm{MWe}$ ) of the nominal power, and compensating for the missing power from the plasma (decay heat during dwell time is only $1 \%$ of the nominal power) $[6,7]$. The results of EBSILON were used for analyses with thermal hydraulic system codes such as APROS [8] or RELAP5-3D (PhD thesis in print).

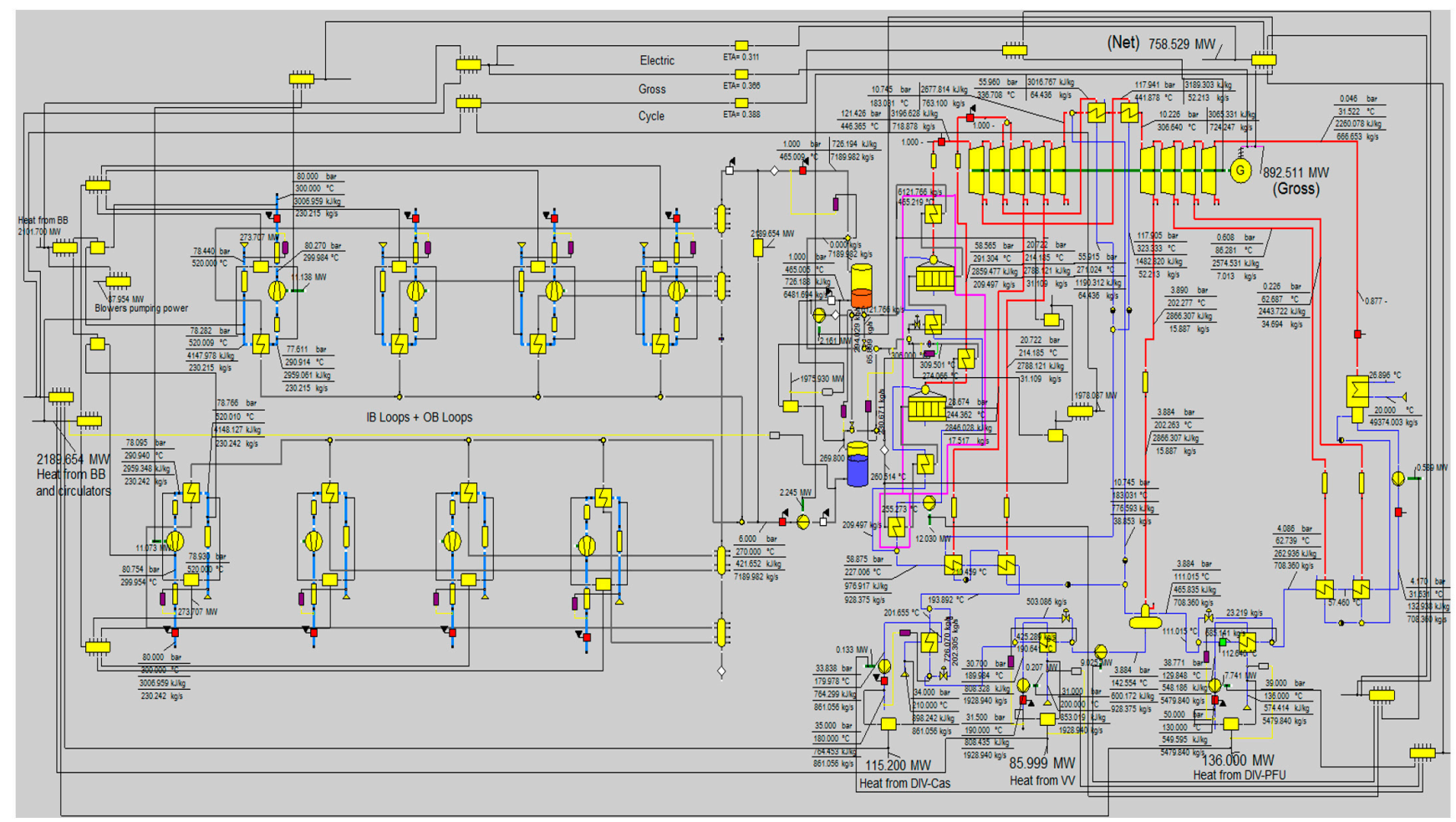

Figure 3. DEMO HCPB BOP ICD with optimized PCS and $90 \%$ power output during pulse and dwell.

\subsubsection{MATLAB/SIMULINK Model Results}

Starting from the EBSILON results, a more detailed model was established using MATLAB/SIMULINK [9]. The schema for the HCPB-ICD variant between PHTS and PCS via IHTS is presented in Figure 4. The simulation model of the IHTS was joined with the model of the modified PCS Rankine cycle. The coupling of IHTS with PCS takes place via the thermal ports for the heat transfer from the side of the preheater $(\mathrm{PH})$, steam generator (SG), and steam heater (SH) of IHTS to that of the PH, SG, and SH of the PCS. Only heat transfer was simulated, taking into consideration the heat transfer from HITEC molten salt to water. The temperature source as the heat input was eliminated and was substituted with solid connection lines via the ports $\mathrm{H}$. Due to modeling conditions, the standard water/steam property block was excluded, as only one solver block can be used. Hence, in this case the customized block of newly developed HITEC properties remained. The properties of water/steam were considered as constants due to constant heat capacity and mass flows from the side of IHTS SG. 


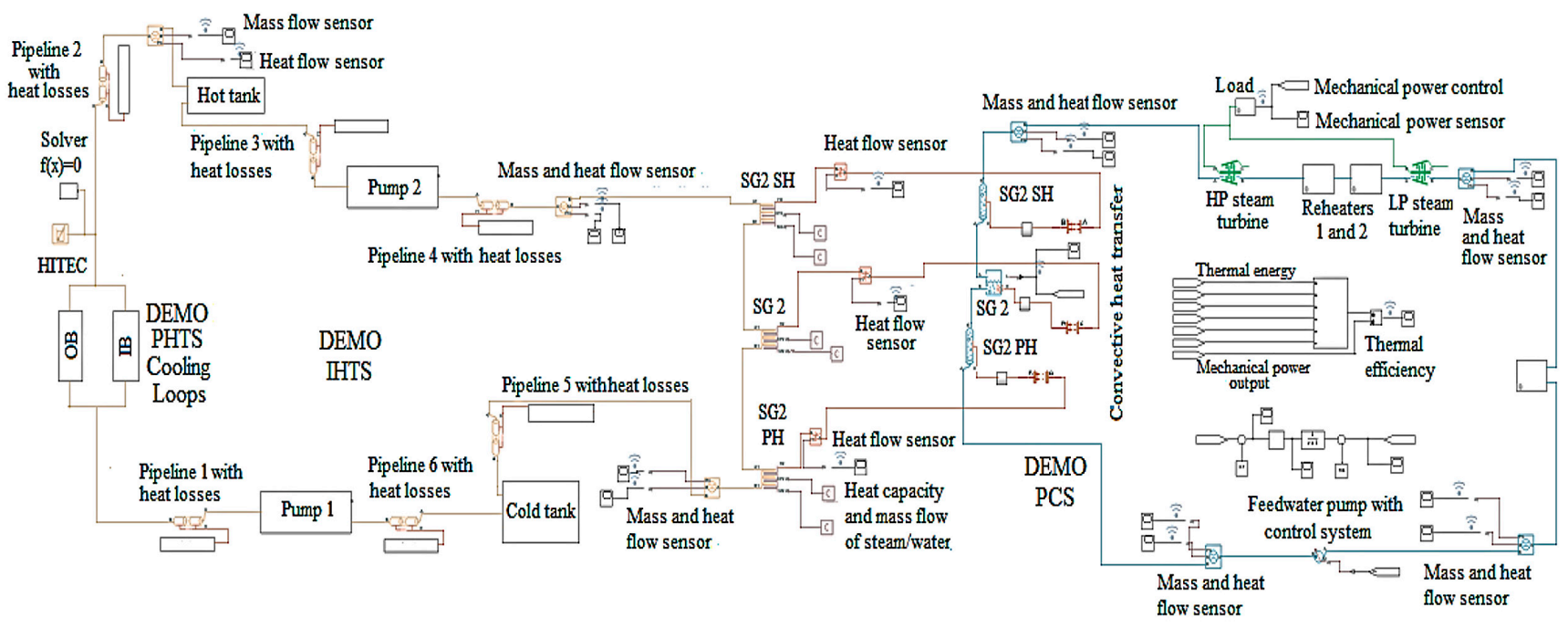

Figure 4. MATLAB/SIMULINK model of DEMO BOP ICD concept: the connection of DEMO PHTS with PCS via IHTS.

In a second step, the IHTS model was coupled to a DEMO PCS based on the Rankine cycle concept, using a specific MATLAB/SIMULINK coupling tool named thermal port. The obtained energy balance for the DEMO BOP energy transfer chain during the DEMO pulse operation revealed that the dynamic simulations enabled a good evaluation of the DEMO BOP operation parameters, in order to optimize the process in terms of power change rate. The results of the simulations confirmed the stability of DEMO BOP energy transfer chain during the pulse and dwell operation of the TOKAMAK reactor using the ICD concept. The simulations confirmed the fact that the application of the IHTS is an essential solution to ensure a stable operation of the steam turbines and electric generators [9]. To realize stable operation of the energy transfer chain, it is important to ensure the operation stability of the generator both from the "heat-mechanical energy side" of the DEMO constellation and from the "electrical energy side" of the grid [10].

Taking into account these promising results, in a next step, system codes such as RELAP5-3D or TRACE were used to provide overall simulations and support for the experimental verification using the new research infrastructure HELOKA-US, as described in in detail in Section 4.

\subsection{Design and Layout}

The reference version of HCPB-ICD (see Figure 5) uses an IHTS-ESS operating with molten salt (HITEC) to decouple regular plasma strokes from the PCS. The IHTS design is based on the current technology used in CSP plants (150 MWe power and up to $1 \mathrm{GWh}_{\text {th }}$ storage energy). As already mentioned previously, for such a concept, detailed plant functional design was performed by KIT using EBSILON software (see Figure 3 for pulse time operation) supported by industry with respect to the power conversion system.

\subsubsection{Main Heat Train PHTS-IHTS/ESS-PCS}

As shown in Figure 2, BOP has to supply cooling to the FW and BB using helium as the HTF and to the divertor and the vacuum vessel using water. For the BB PHTS, the heat sink is the IHTS, while the energy of the DIV PHTS and the VV PHTS is transferred via heat exchangers to the feedwater train of the PCS, thus enhancing the overall system efficiency. 


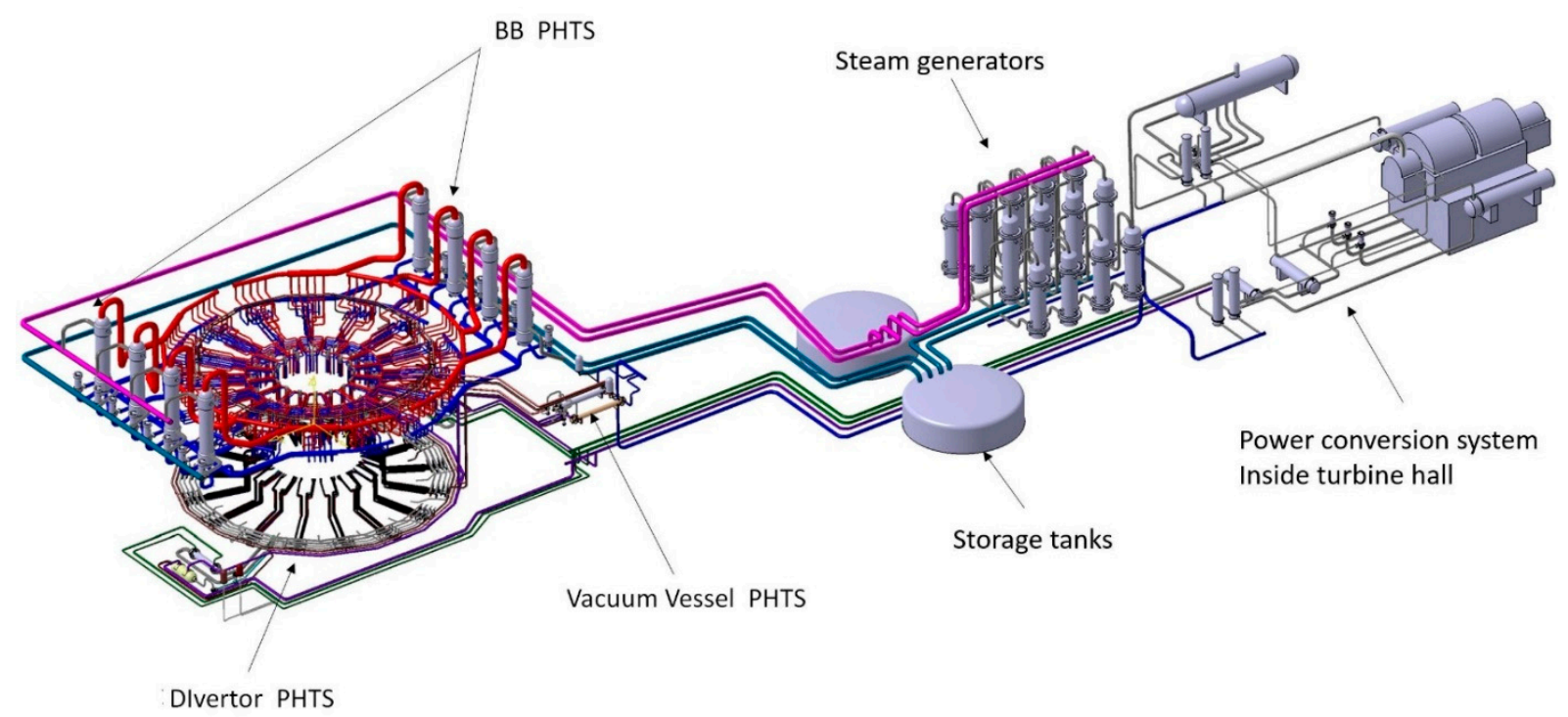

Figure 5. Schematic layout of DEMO HCBP ICD design including all PHTS systems, the IHTS with two tank ESS, and the PCS up to the AC generator.

The FW/BB-PHTS (helium) is segmented into eight loops (see Figure 5, left side) each providing heat transfer to two sectors (six outboard plus four inboard segments) via top/upper ports [6]. This configuration was necessary to keep the dimensions of the components small and to minimize challenges and risks of loss-of-coolant accidents, as well as blower failure, with subsequent damage of the first wall due to a lack of cooling. The drawback is a more complicated pipe routing from the TOKAMAK to the heat exchanger and blower compartments. The segmentation offers benefits with respect to safety, maintenance, and component size, thus restricting valves to fill and drain lines. The HTF velocity in the main coolant line is kept limited, thus leading to feasible pipe diameters $(<1.3 \mathrm{~m})$. For safety reasons, each loop incorporates two helium blowers. They can be aligned in parallel or in series and incorporate an internal bypass valve, such that one blower alone can provide sufficient cooling to the BB to ramp down correctly without unintended plasma breakdown. For the heat exchanger between helium and solar salt (HITEC), two possible solutions exist (spiral and once through) [7]. For a final selection, the dynamic behavior of both solutions has to be investigated.

As depicted in Figure 5, the IHTS gathers the thermal energy from the BB PHTS in the ESS during pulse, manages the inlet temperature to the BB-PHTS via the HX secondary-side inlet temperature, and then transfers the thermal energy to the steam generator/superheater as requested by the PCS. During dwell, the HITEC flow rate is adjusted to the need of the BB decay heat removal using a dedicated small pump. On the right side, as in the pulse time, it follows the requests of the PCS. To achieve such a decoupling function, two or three HITEC pumps are foreseen, operating independently of each other. For operation and safety reasons, each pump is foreseen as a twin-pump. For simplification, the ESS is realized as a classical two-tank solution. For the molten salt (HITEC) steam generator, a technical offer and a price indication from Company Siemens AG are available.

During p-CDP, the PCS (Figure 3, right side) was optimized on the basis of the available energy sources. All relevant usable energy (exergy) sources are included at optimal temperature and power level, even if additional components become necessary to avoid investment toward additional cooling capacity. Lastly, the detailed design proposed by an industrial partner (SIEMENS AG) provided substantial progress in efficiency due to the fine optimized turbine-feedwater train. The company Siemens AG supplied the design for both the turbogenerator and the steam generator, as the interaction of these two large components has a high impact on system performance and space and cost optimization. 
The gross output of the SIEMENS SST5-6000 turbogenerator during dwell time is now even higher due to the reduced BB PHTS circulation power.

\subsubsection{Secondary Heat Train PHTS-PCS}

In the DEMO HCPB BOP, secondary heat sources are water-cooling systems for the divertor and the vacuum vessel. As for the DIV-CAS and DIV-PFU PHTS, BOP design follows the requirement of the DIV, thus defining system pressure, as well as inlet and max. tolerable outlet temperature for the divertor cassettes and plasma facing units. The heat is transferred via heat exchangers in the TOKAMAK building to the feedwater loop as indicated in Figure 5, thus contributing to the PCS power output.

VV PHTS provides water-cooling to the vacuum vessel at an inlet temperature of $190{ }^{\circ} \mathrm{C}$ by forced convection. The heat is transferred via heat exchanger in the TOKAMAK building to the feedwater loop, thus also contributing to the PCS power output.

\subsection{Open Issues}

The DEMO BOP project is on a solid path and is close to reaching the conceptual design phase. One of the aims of the preconceptual design phase was to assess the readiness level at different scales and to review the maturity of subsystems and components. In order to be able to make an adequate and useful statement here, it is necessary to consider not only the TRL for new technologies, but also the SRL for the BOP overall-/sub-systems, as well as the IRL for proven technologies, which must be integrated into the system (according to the operating conditions).

One result of the investigation was that, with regard to the IRL, the main interfaces between PHTS and IHTS (Main HX) and between IHTS and PCS (MSSG) are to be assessed as critical. Another result was that the IHTS, the He-compressors, and their operating behavior must be investigated in an experimental facility in order to achieve a higher IRL. The PCS was also rated as being noncritical.

Another aim of the preconceptual design phase was to identify design optimizations or alternatives for the identified critical components. For the important and critical interface component "Main-HX", four design variants were examined, compared, and evaluated. It was found that the "plate and shell design", which was not previously investigated, is not only compact but also proven in nuclear powerplants and, therefore, has a high reliability. It is recommended to further investigate this design alternative under DEMO conditions.

The other important and critical interface component "molten salt steam generator (MSSG)" is currently based on an SG design from the CSP industry, which was indeed not upscaled or adapted, but multiplied in a modular approach to match DEMO requirements. This enables various optimization possibilities, including a reduction in the number of MSSGs and, thus, the complexity and the space requirement of a modular arrangement. Another optimization aspect is to be found in the actual design, i.e., the compactness of the MSSG in terms of surface area per unit volume. In addition to the aforementioned performance optimizations, the costs of the MSSG system can be reduced to one-third of the price by changing the material from high-alloy stainless steel to common carbon steel. One prerequisite is to assure that no chloride impurities in the HITEC molten salt are present.

The molten salt storage and transfer system components of the current IHTS concept are based on today's CSP technology. In addition to the common two-tank-thermal storage system, the pros and cons of a single-tank (i.e., thermocline) and a modular approach with several smaller tanks (i.e., multi-tank) were indicated. The comparison showed that a thermocline setup has a comparatively low TRL and IRL, whereas a multi-tank setup does have several advantages compared to the currently planned common two-tank system. In the context of the multi-tank system, the required molten salt transfer system can also be optimized. Here, centrifugal pumps can be used at ground level or on a small buffer tank, which reduces operating costs and simplifies maintenance and operation. 
Another aim of the preconceptual design phase was a market survey in order to identify potential suppliers for the He-compressors that are required for the FW /BB-PHTS loop. In general, several companies are available that can provide He-compressors for DEMO application. However, there is currently no focus on producing such large Hecompressors due to currently missing application. Nevertheless, positive feedback from the market with several companies was received, while also obtaining budgetary price offers.

\section{Experimental Verification}

While the secondary heat train uses technology with an industrial readiness level, some primary heat components of the transfer train such as the helium HITEC primary heat exchanger, the HITEC steam generator, or the helium blowers have to be evaluated and optimized in the conceptual design phase. This includes scaling and selecting the type of the components to fulfill the DEMO requirements. Furthermore, the interplay of the different systems has to be investigated and optimized. Here, the expertise at KIT on helium system operation (HELOKA-HP [11], KATHELO [12], and HEMAT [13]), as well as the expertise in the high-temperature molten salt field (LIVE [14]), was favorably combined within the HELOKA-US project, as explained below.

For HELOKA-US a scaling factor of 1000 for power (compared to DEMO HCPB BOP) was selected, bringing one FW/BB-PHTS loop down to the values listed in Table 3. The vertical scaling, which is only necessary for the HITEC section, was set to $<10$, limited by the available location in the HELOKA-HP building.

Table 3. Main data for HELOKA-US dimensioning.

\begin{tabular}{cccc}
\hline & IHX Test Section & Molten Salt Loop & Cooling Loop (Water) \\
\hline Thermal power $(\mathrm{kW})$ & \multicolumn{2}{c}{$250-280$} & $<300$ \\
\hline Temperature $\left({ }^{\circ} \mathrm{C}\right)$ & $300-550$ & $300-465$ & $10-80$ \\
\hline Pressure $(\mathrm{bar})$ & 80 & $<6$ & $5-12$ \\
\hline Mass flow rate $(\mathrm{kg} / \mathrm{s})$ & 0.24 & 1.10 & $<3$ \\
\hline
\end{tabular}

\subsection{Component Test}

HELOKA-US Phase 1a (see Figure 6, left) comprises the construction and commissioning of the molten salt (MS) loop (Intermediate Heat Transfer System-IHTS) to test and optimize the molten salt side of the Helium-HITEC heat exchanger. The main issue in the MS loop is the heat transfer to the molten salt, which has to be checked and optimized for conditions corresponding to all DEMO states of operation. Thus, an electrical heating system allows simulating the frequent operational transitions between pulse and dwell phases. That approach has the advantage that several configurations can be tested and easily coupled to the heating device without operating of costly helium loop.

\subsection{System Tests}

After a scientific review of Phase 1 around 2024, HELOKA-US Phase 2 will be focused on a prototypical dynamic temperature-adaptive helium blower test. Here, a prototypic design for DEMO will be scaled down and connected to the helium supply and pressure control system of HELOKA on one side and to the molten salt loop on the other side. To simulate the IHTS, a thermal energy storage system (ESS) will be enclosed as shown in the schematics of Figure 7. The full pilot plant will then allow simulating fast transients and operational transitions to qualify the DEMO HCPB BOP design and optimization, as well as the system and safety codes necessary to foster BOP simulation and, later on, safety assessments. 
Phase 1a: HX molten salt side

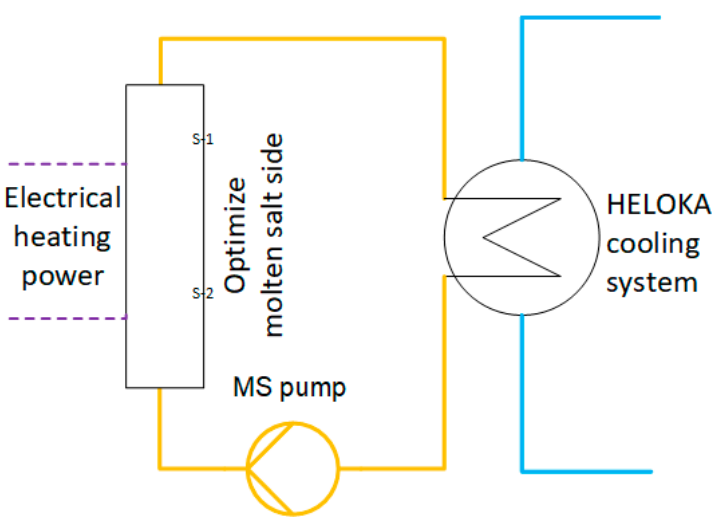

Phase 1b: Test PHTS-IHTS HX

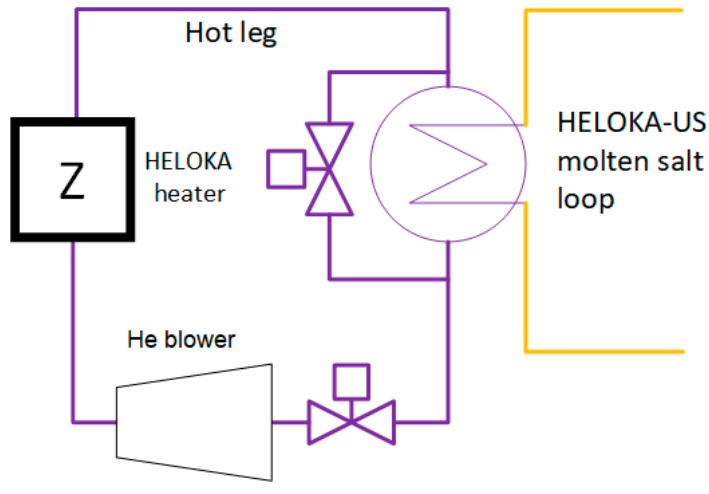

Figure 6. HELOKA-US Phase 1 subdivided into HX qualification and He HX plus blower tests.

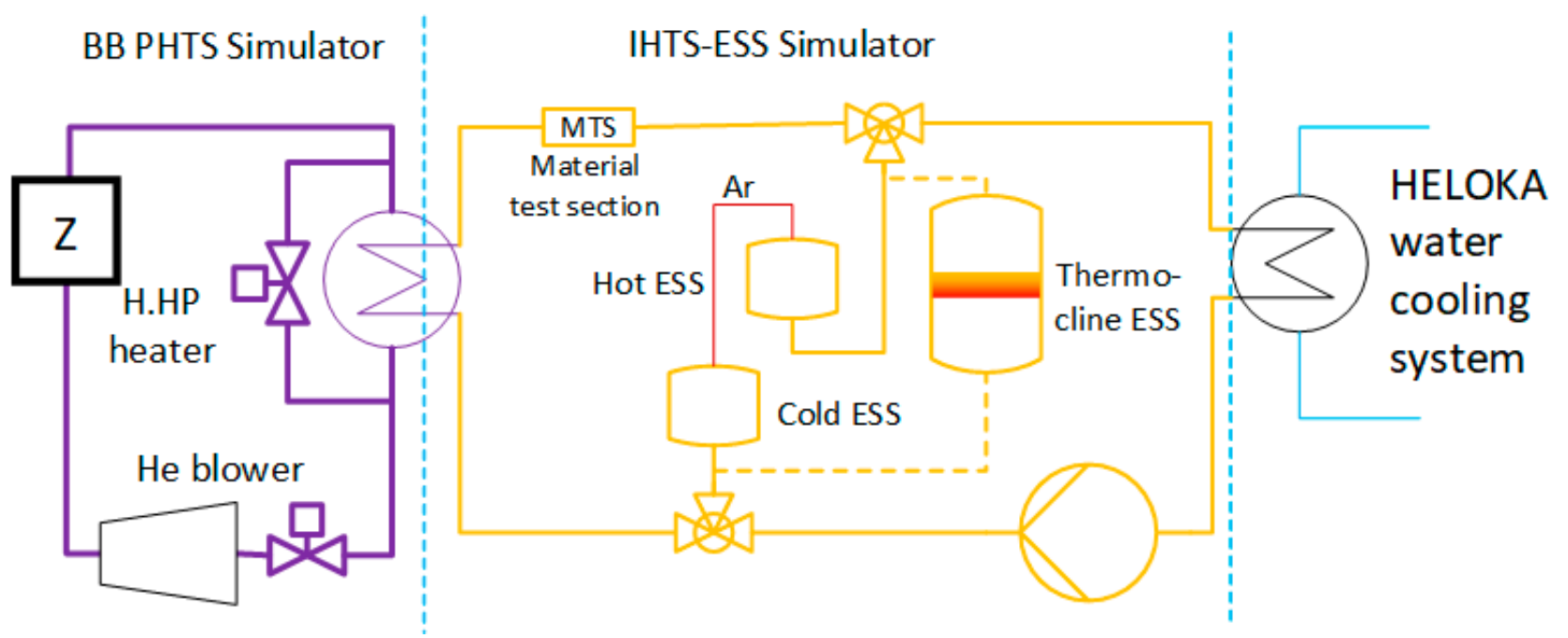

Figure 7. Configuration of HELOKA-US Phase 2 indicating the three systems: PHTS-IHTS/ESS-PCS (only cooling).

As a future extension of Phase 2, the connection to the HELOKA cooling system can be replaced by a power conversion system to demonstrate the whole heat and power train for DEMO BOP.

\section{Summary and Conclusions}

Within the pre-conceptual design phase, the DEMO balance of plant of the HCPB breeding blanket concept was developed and constantly adapted to the requirements of the different heat sources. In addition to the primary heat source from the BB, which is transferred to the IHTS with the ESS and to the PCS, the secondary heat sources are directed via HX to the feedwater train of the PCS. The selected variant ICD was considered as a reference design for the DEMO HCPB BOP concept.

Following the technological approach, the first step was to use simulating tools (EBSILON and MATLAB/SIMULINK) to come up with a feasible HCPB-ICD configuration. Afterward, the best technological and available components were found, where feedback from our industrial partners played an important role. After the assessment and comparison of the different variants investigated, the various criteria used (TRL, IRL, and SRL) led to selecting the reference configuration as the indirect coupling design. Among the four investigated variants, the ICD concept provided the highest and most flexible electrical power output of DEMO, varying between 90\% (pulse: 760 MWe) and 104\% (dwell: 890 MWe). The higher value in the dwell time originates from the lower required 
He circulator power, due to fusion power lacking. Therefore, the subsequent steps in the consolidation of this DEMO HCPB BOP design involve the experimental validation of those critical components not yet demonstrated to perform successfully under DEMO operation conditions. This will be achieved in the HELOKA-US project for the Helium blower and the intermediate heat exchanger, whereas Phase 2 will be devoted to the interplay of the different systems and components.

Author Contributions: Conceptualization, W.H., E.B. and S.P.-M.; EBSILON analysis and results, E.B.; MATLAB/SIMULINK analysis and results, M.-V.B.; Experimental verification, W.H. and S.P.-M.; writing—original draft preparation, W.H., E.B. and S.P.-M.; writing—review and editing, W.H., E.B. and S.P.-M.; supervision, W.H.; project administration, W.H. All authors have read and agreed to the published version of the manuscript.

Funding: This work was carried out within the framework of the EUROfusion Consortium and received funding from the Euratom research and training program 2014-2018 and 2019-2020 under grant agreement No 633053. The investment of HELOKA-US is sponsored by EUROfusion BOP (FP9 from 2021 to 2027, contract to be signed) and by the KIT funding from the Helmholtz Program FUSION.

Institutional Review Board Statement: Not applicable.

Informed Consent Statement: Not applicable.

Data Availability Statement: Data sharing is not applicable to this article.

Acknowledgments: This work was carried out within the framework of the EUROfusion Consortium and received funding from the Euratom research and training program 2014-2018 and 2019-2020 under grant agreement No 633053. The views and opinions expressed herein do not necessarily reflect those of the European Commission.

Conflicts of Interest: The authors declare no conflict of interest.

$\begin{array}{ll}\text { Abbreviations } & \\ \text { ACP } & \text { Activated corrosion products } \\ \text { AHS } & \text { Auxiliary Heater System (to cope with dwell time power lacking) } \\ \text { AUXB } & \text { Auxiliary boiler } \\ \text { BB } & \text { Breeder blanket } \\ \text { BOP } & \text { Balance of Plant } \\ \text { CAS } & \text { Cassettes (part of divertor) } \\ \text { CDP } & \text { Conceptual design phase } \\ \text { CSP } & \text { Concentrating solar power } \\ \text { CWS } & \text { Coolant water system } \\ \text { DCD } & \text { Direct coupled design } \\ \text { DIV } & \text { Divertor } \\ \text { ESS } & \text { Energy storage system } \\ \text { FPP } & \text { Fusion powerplant } \\ \text { FW } & \text { First wall } \\ \text { HCPB } & \text { Helium cooled pebble bed (blanket) } \\ \text { HCPB ICD BOP } & \text { HCPB indirect coupling design balance of plant } \\ \text { HELOKA-US } & \text { Helium Loop Karlsruhe Upgrade Storage } \\ \text { HP } & \text { High pressure } \\ \text { HT } & \text { High temperature } \\ \text { HTF } & \text { Heat transfer fluid } \\ \text { HX } & \text { Heat exchanger } \\ \text { ICD } & \text { Indirect coupled design } \\ \text { IHTS } & \text { Intermediate heat transfer system (based on molten salt as HTF) } \\ \text { IHX } & \text { Intermediate heat exchanger } \\ & \end{array}$




$\begin{array}{ll}\text { IRL } & \text { Integration readiness level } \\ \text { LP } & \text { Low pressure } \\ \text { MS } & \text { Molten salt (HITEC) } \\ \text { NPP } & \text { Nuclear powerplant } \\ \text { OTGS } & \text { Once through steam generator } \\ \text { p-CDP } & \text { Preconceptual design phase } \\ \text { PCS } & \text { Power conversion system } \\ \text { PES } & \text { Plant electrical system } \\ \text { PFU } & \text { Plasma facing units } \\ \text { PH } & \text { Preheater } \\ \text { PHTS } & \text { Primary heat transfer system } \\ \text { SG } & \text { Steam generator } \\ \text { SH } & \text { Steam heater } \\ \text { SR } & \text { Steam reheater } \\ \text { SRL } & \text { System readiness level } \\ \text { ST } & \text { Steam turbine } \\ \text { TRL } & \text { Technical readiness level } \\ \text { VV } & \text { Vacuum vessel } \\ \text { VVPSS } & \text { Vacuum vessel pressure suppression system }\end{array}$

\section{References}

1. Frederici, G. Overview of the design approach and prioritization of R\&D activities towards an EU DEMO. Fusion Eng. Des. 2016, 109, 1464-1474. Available online: https:/ / www.sciencedirect.com/science/article/pii/S0920379615303835 (accessed on 11 October 2021).

2. Barucca, L.; Bubelis, E.; Ciattaglia, S.; D'Alessandro, A.; Del Nevo, A.; Giannetti, F.; Hering, W.; Lorusso, P.; Martelli, E.; Moscato, I.; et al. Pre-conceptual design of EU DEMO balance of plant systems: Objectives and challenges. Fusion Eng. Des. 2021, 16, 112504. Available online: https://www.sciencedirect.com/science/article/abs/pii/S0920379621002805 (accessed on 11 October 2021). [CrossRef]

3. 8th Action Plan of The European Green Deal. Available online: https:/ / ec.europa.eu/environment/pdf/8EAP/2020/10/8EAPdraft.pdf (accessed on 11 October 2021).

4. International Workshop on Advanced Reactor Systems and Future Energy Market Needs, Paris, France, 12 April 2017. Available online: https:/ / www.oecd-nea.org/jcms/pl_30808/workshop-arfem-19-terrestrial-energy (accessed on 11 October 2021).

5. Hering, W.; Bubelis, E. BOP-DEF-2-CD1, BOP-2.1-T060-D001: HCPB PHTS \& PCS Rationale for the Selection of the Variant, EUROfusion Pre-CD Phase; KIT Internal Report: FUSION 517, INR 13/20; KIT: Karlsruhe, Germany, in preparation.

6. Hering, W.; Jin, X.Z.; Bubelis, E.; Perez-Martin, S.; Ghidersa, B.E. Operation of the Helium Cooled Demo Fusion Power Plant and Related Safety Aspects, IAEA-Tecdoc-13657. 2020. Available online: https://www.iaea.org/publications/13657/challenges-forcoolants-in-fast-neutron-spectrum-systems (accessed on 11 October 2021).

7. Bubelis, E.; Hering, W.; Perez-Martin, S. Industry supported improved design of DEMO BOP for HCPB BB concept with energy storage system. Fusion Eng. Des. 2019, 146, 2334-2337. [CrossRef]

8. Malinowski, L.; Lewandowska, M.; Bubelis, E.; Hering, W. Design and analysis of the secondary circuit of the DEMO fusion power plant for the HCPB BB option without the energy storage system and with the auxiliary boiler. Fusion Eng. Des. 2020, 160, 112003. [CrossRef]

9. Bologa, M.-V.; Stieglitz, R.; Hering, W.; Bubelis, E. Parameter Study and Dynamic Simulation of Current DEMO Intermediate Heat Transfer and Storage System Design via MATLAB/Simulink, Poster Session at 14th International Symposium on Fusion Nuclear Technology (ISFNT-14), Budapest, Hungary, 2019. Available online: https://publikationen.bibliothek.kit.edu/10000991 $97 / 45106288$ (accessed on 11 October 2021).

10. Bologa, M.-V.; Bubelis, E.; Hering, W. Parameter Study and Dynamic Simulation of the DEMO Intermediate Heat Transfer and Storage System Design Using MATLAB/Simulink. J. Fusion Eng. Des. 2021, 166, 112291. [CrossRef]

11. Ghidersa, B.E.; Ionescu-Bujor, M.; Janeschitz, G. Helium Loop Karlsruhe (HELOKA): A valuable tool for testing and qualifying ITER components and their He cooling circuits. Fusion Eng. Des. 2006, 81, 1471-1476. [CrossRef]

12. Ghidersa, B.E.; Jin, X.; Rieth, M.; Ionescu-Bujor, M. KATHELO: A new high heat flux component testing facility. Fusion Eng. Des. 2013, 88, 854-857. [CrossRef]

13. KIT-HEMAT Facility. Available online: https://www.inr.kit.edu/english/630.php (accessed on 11 October 2021).

14. Gaus-Liu, X.; Bigot, B.; Journeau, C.; Payot, F.; Cron, T.; Clavier, R.; Peybernes, M.; Angeli, P.E.; Fluhrer, B. Experiment and Numerical Simulations on SFR Core-catcher Safety Analysis after Relocation of Corium; FR-22: IAEA-CN-291/336; IAEA: Vienna, Austria, in preparation. 